\title{
Planificación urbana y salud pública
}

El diseño de nuevos sistemas de transporte y -con mayor razón- los cambios significativos en los existentes, como es el caso del Transantiago, se inscriben en un contexto de planificación urbana y su éxito depende, en gran medida, de su capacidad de resolver numerosas situaciones que determinan las condiciones en que la población desarrolla su vida cotidiana.

La interacción entre salud pública y planificación urbana tiene una larguísima historia y cada día adquiere mayor importancia y nuevas dimensiones. En 1854, el médico inglés John Snow utilizó el mapeo geográfico para identificar una bomba de agua en Londres, que resultó ser la fuente de contagio de una epidemia de cólera. En esa misma época, urbanistas tales como Frederick Law Olmsted validaron la importancia de integrar estas disciplinas al reconocer la significación de los espacios comunitarios para la salud física y mental, creando cientos de parques, incluyendo el Parque Central de Nueva York, en Estados Unidos. Otro hecho interesante de destacar es que de los siete fundadores de la Asociación Americana de Salud Pública el año 1872, dos eran urbanistas, uno arquitecto y otro experto en vivienda. Recientemente, cabe señalar la estrecha relación entre estas disciplinas en la formulación del concepto y la expansión del movimiento de Ciudades Saludables, que comenzó en Europa y Estados Unidos en los años 80, y que hoy se extiende a más de mil ciudades en todo el mundo.

La planificación urbana es un campo multidisciplinario, orientado a mejorar el bienestar de las personas y comunidades mediante la creación de espacios y lugares agradables, saludables, con menores desigualdades, eficientes y atractivos, gracias al desarrollo de planes de diferente magnitud, que incluyen las áreas de transporte, vivienda, equipamiento comercial, protección ambiental, utilización de los recursos naturales e infraestructura de salud, entre otras. Esto no debe sorprendernos, porque la planificación urbana y la salud pública comparten misiones y perspectivas tales como la satisfacción del bienestar humano, enfatizan el diagnóstico de las necesidades y de la provisión de servicios adecuados, manejan sistemas sociales complejos, intervienen a nivel poblacional y se nutren de la participación comunitaria privilegiando la satisfacción de las necesidades de la población más vulnerable.

Contar con un sistema de transporte de buena calidad y eficiente constituye un pilar fundamental del desarrollo urbano y, en particular, del funcionamiento de la ciudad. Su expansión, modernización y diversificación a lo largo del tiempo también está documentada para las grandes metrópolis, quedando en evidencia que los avances no han sido fáciles de implementar y los problemas no simples de resolver. Sin embargo, la relación entre sistemas transporte y condiciones de salud, que ha recibido escasa atención, con excepción de los efectos sobre la calidad del aire y la subsecuente contaminación ambiental, comienza a interesar a las autoridades políticas en diferentes partes del mundo, abriendo oportunidades que debiéramos tener en consideración en nuestro país al iniciarse un cambio tan significativo en el transporte en Santiago.

Sólo mencionaremos dos publicaciones recientes que ilustran lo que se puede lograr si se conforman instancias de colaboración entre los especialistas, los decisores políticos y las organizaciones sociales en torno a una política con objetivos comunes.

La organización Smart Growth B.C. y la Universidad de British Columbia, de Canadá, publicaron el informe "Promoting Public Health Through Smart Growth", que documenta cómo el contexto urbano configura las opciones de transporte y, en consecuencia, la salud de la población beneficiaria. Igualmente, examina los resultados de investigaciones para una serie de condiciones de salud 
relacionadas con el transporte, entre las que destacan: actividad física y obesidad, calidad del aire, seguridad en el tránsito, ruido, calidad del agua, salud mental y capital social. El documento concluye que aquellas comunidades que han crecido de manera armónica son más saludables y que ello se logra principalmente mediante la modificación de sus conductas de transporte.

El otro estudio, publicado en el J. Epidemiol. Community Health el año 2004, señala que la realización de la Evaluación del Impacto en Salud de la Estrategia de Transporte de Londres, elaborado por el alcalde de esa ciudad, fue exitosa en influenciar dicha estrategia, resultando en mejoramientos significativos desde el punto de vista de la salud. Las recomendaciones más significativas se refirieron a promover un transporte apropiado hacia los lugares de trabajo y establecimientos educacionales; otorgar prioridad a la infraestructura y servicios que beneficien a las comunidades con mayor deprivación; aumentar la promoción del caminar y del uso de la bicicleta; y el compromiso de establecer mecanismos de evaluación de los impactos de la estrategia sobre la salud, por una parte, y de su implementación, por otra.

En síntesis, en nuestro país enfrentamos, concordante con lo que ha ocurrido en otras ciudades del mundo, la puesta en marcha de una profunda transformación del sistema de transporte colectivo en la ciudad de Santiago, el que está teniendo serios problemas de diseño e implementación. Este proyecto ha dejado en evidencia grandes deficiencias en la concepción y desarrollo urbano de nuestra capital, gestadas a lo largo de décadas, asociada a una cultura de cómo trasladarnos profundamente enraizada en nuestra idiosincrasia, que al igual que en otras partes del mundo privilegia cada vez más el individualismo.

He aquí un desafío y una responsabilidad para la salud pública en los diferentes ámbitos de su quehacer. Se torna imperativa la colaboración multidisciplinaria al interior del sector salud, pero de manera prioritaria más allá de éste, con las autoridades nacionales y locales responsables, expertos en transporte y urbanismo, por mencionar sólo algunos de los numerosos actores comprometidos.

Las universidades podemos formar recursos humanos, investigar y oportunamente realizar las evaluaciones que se requieren para medir el impacto del Transantiago en la salud no sólo de la población que lo utiliza, sino también de quienes se benefician indirectamente de él. 